Talía. Revista de estudios teatrales

ISSN-e 2659-806X

\title{
Lope de Vega y Calderón también pueden ser para niños
}

\author{
Almudena García González*
}

Recibido: 27 de enero de 2020 / Aceptado: 30 de junio de 2020

Resumen: El repertorio de teatro infantil y juvenil en la escena actual es realmente diverso. Y entre todas las obras que podemos ver encontramos un número considerable de montajes que son adaptaciones de obras clásicas. Sin embargo, en muchas ocasiones no son textos dramáticos de los que parten, sino textos narrativos como El Quijote o los cuentos de Perrault. Y en el caso de ser una pieza dramática, Shakespeare y su tragedia Romeo y Julieta son el autor y la obra que más vemos representados. Este trabajo analiza esta situación y trata de mostrar, a través de montajes innovadores llevados a cabo por compañías como Pie Izquierdo o Tropos Teatro de títeres, que el teatro de los dramaturgos barrocos españoles como Lope de Vega y Calderón, también puede ser una apuesta excelente para divertir y enseñar valores universales al público más joven.

Palabras clave: Teatro infantil y juvenil; Teatro clásico; Adaptación; Lope de Vega; Calderón.

\section{[en] Lope de Vega and Calderón also can be for children}

\begin{abstract}
In the current stage, the repertoire of youth and children's theatre is diverse. Among all the plays we can find, there are several staging which are classic works adaptations. Although, several times, they don't come from plays, but from narrative works as El Quijote or Perrault's tales. And, in case of being from a play, it is Shakespeare and his tragedy Romeo and Juliet, the most play author and text. This article analyses this condition and tries to show, through innovative staging conduct for theatre companies like Pie Izquierdo or Tropos Teatro de títeres, that Spanish Golden Age playwriters like Lope de Vega or Calderón also can be an excellent investment to entertain and teach universal values to youth and children's public.
\end{abstract}

Keywords: youth and children's theatre; Golden Age theatre; adaptation; Lope de Vega; Calderón.

Cómo citar: García González, A. (2020). Lope de Vega y Calderón también pueden ser para niños, en Talia. Revista de estudios teatrales, 2, 45-53.

Desde hace ya unos años, la consideración del teatro infantil ha ido evolucionando y prestigiándose y la oferta que podemos encontrar en las carteleras resulta cada vez más variada y de mayor calidad. Cada vez son más las compañías que combinan en su repertorio montajes para un público adulto, con otros para público infantil o familiar e, incluso, que han evolucionado hacia la especialización en teatro infantil. Así, por ejemplo, este sería el caso de la compañía vallisoletana Teloncillo, creada en 1968, profesional desde 1976 y, a partir de 1996, dedicada en exclusiva a la creación de espectáculos familiares y para la primera infancia ${ }^{1}$ de excelente calidad.
Por otro lado, el teatro clásico también podemos decir que vive un buen momento: la Compañía Nacional de Teatro Clásico agota localidades en la mayor parte de los espectáculos propuestos y, en el verano de 2019, han celebrado una nueva edición dedicada al teatro de los Siglos de Oro cinco festivales repartidos por la geografía española: Cáceres, Alcalá, Almagro, Olmedo y Olite han acogido sus ediciones número 30, 19, 42, 14 y 20, respectivamente. Además, se han podido ver ciclos de teatro áureo en otras ciudades, como en Almería, en torno a las Jornadas de Teatro del Siglo de Oro, o el que anualmente se programa en el Teatro de Rojas de Toledo en el último trimestre del año. Aunque es muy habitual en estos festi-

\footnotetext{
* Universidad de Castilla-La Mancha Email: Almudena.Garcia@uclm.es

1 Por el 25 aniversario de la compañía, el Ayuntamiento de Valladolid publicó un libro sobre la historia de Teloncillo. En el segundo tomo, que abarca su historia de 1996 a 2015, podemos encontrar información muy valiosa de su recorrido como compañía de teatro infantil. 
vales encontrar varios montajes de Shakespeare o alguno de Molière, principalmente, son textos de nuestros dramaturgos barrocos, Lope, Calderón, Tirso de Molina, Rojas Zorrilla..., los que componen esencialmente las carteleras de estos prestigiosos encuentros.

Conscientes de la evolución y de la demanda de teatro para un público infantil o familiar, los festivales antes nombrados han ido incorporando a su programación talleres y espectáculos con el objetivo de que niños y jóvenes también puedan conocer, deleitarse y aprender de los clásicos. En este sentido, habría que destacar al festival de Almagro. Una revisión de la programación del Festival de Teatro Clásico de Almagro en los últimos 20 años muestra cómo por parte de los diversos directores del Festival ha existido interés por acercar el teatro a los más pequeños, pues se pueden encontrar una media de entre tres y cuatro representaciones infantiles por año, además de la presencia de talleres para niños sobre diversas materias teatrales en varias de las ediciones. Pero es desde 2012 cuando el teatro infantil se asienta y cobra especial relevancia con la creación de un espacio propio dentro de la programación general del Festival: el certamen de Barroco Infantil. ¿Por qué puede considerarse especialmente relevante este espacio si no es algo nuevo dentro del Festival de Almagro ni exclusivo de este?

La creación de Barroco Infantil supone que se considera que este teatro debe tener su propio espacio, no ser un apartado más de la programación general, con todo lo que ello conlleva:

- Un nombre (más allá de los genéricos "teatro infantil" o "teatro familiar") y un logo propios.

- Un aumento del número de espectáculos que lo conforman, que se duplica de tres a seis.

- Una convocatoria y un proceso de selección propios, diferentes de los de la programación general.

- La creación de un premio ligado a este espacio para el espectáculo más votado por un jurado específico, formado por una representante de la organización del Festival, dos profesionales del mundo teatral y dos niños. Cada año, estos dos últimos colectivos cambian.

- Una finalidad artística, más allá de la de ofrecer entretenimiento a los más pequeños durante el festival y el intento de captar futuros espectadores.
Desde su creación, como acabamos de indicar, la dirección del Festival lanzó una convocatoria propia, es decir, que las obras para Barroco Infantil llevan un proceso de selección aparte de las del resto de la programación. En esta convocatoria cabrían destacar, en especial, dos puntos. El primero, la finalidad con la que se indica que se hace: "promover y favorecer la creación escénica de obras dramáticas sobre el Barroco, destinadas a un público infantil". El segundo, los criterios señalados para valorar las diferentes propuestas: originalidad, creatividad y, en el que se quiere hacer más hincapié: pedagogía. Ambos puntos son muy relevantes por lo que supondría en la concepción de los organizadores del Festival sobre lo que es el teatro infantil: un género que requiere una dedicación y unos profesionales que ofrezcan trabajos de calidad, además de que aprecien y sepan explotar su valor educativo. Según se señala en la presentación de la primera edición, el Festival es consciente de que el público demanda un teatro familiar de calidad, lo que, unido a un crecimiento profesional en el ámbito del teatro infantil en los últimos años, los lleva a considerar que merece la pena la creación de este espacio. Resulta muy positivo que esta idea no solo se haga explícita, sino que sea compartida por quienes tienen los medios para favorecerla e impulsarla. No podemos olvidar que, de los festivales anteriormente citados, Almagro es no solo el más longevo, sino el más conocido tanto a nivel nacional, como internacional y el que dispone de un mayor presupuesto.

A raíz de las situaciones anteriormente expuestas, podríamos pensar que tanto el aumento de demanda y consideración general del teatro familiar, como la profesionalización de los creadores de este teatro, junto con la existencia de espacios concretos de representación que garanticen unas mínimas representaciones a las compañías, podrían haber conllevado la progresiva aparición de adaptaciones de obras de nuestro teatro áureo al público infantil y juvenil. Sin embargo, las carteleras nos muestran un panorama más bien desalentador en este punto. Ya que el certamen de Barroco Infantil es el más especializado y amplio, nos centraremos en las representaciones que se han llevado a cabo en este desde su creación en 2012, hasta la edición de 2019 para presentar una muestra de las adaptaciones de textos clásicos que se están llevando a cabo. Desde su primera edición, se repiten especialmente montajes de los siguientes autores y obras:

Charles Perrault (siete montajes):

\begin{tabular}{|l|l|l|l|}
\hline \multicolumn{1}{|c|}{ Edición } & \multicolumn{1}{|c|}{ Pulgarcito } & \multicolumn{1}{|c|}{ Caperucita Roja } & \multicolumn{1}{|c|}{ La ratita presumida } \\
\hline 2012 & Pulgarcito (Pa Sucat) & & \\
\hline 2014 & Pulgarcito (Teatro Paraíso) & La crónica del lobo (Elfo Teatro) $)^{2}$ & \\
\hline 2017 & & $\begin{array}{l}\text { Lo que nunca se contó (Telonci- } \\
\text { llo) }\end{array}$ & $\begin{array}{l}\text { La ratita presumida (Festuc Tea- } \\
\text { tro) }\end{array}$ \\
\hline 2018 & & Feroz (Belacqua) & $\begin{array}{l}\text { Talisma. Caperucita en Bangla- } \\
\text { desh (Colectivo Ópalo) }\end{array}$ \\
\hline 2019 & & & \\
\hline
\end{tabular}

En este montaje también se versionaban Los siete cabritillos y Los tres cerditos. 
Miguel de Cervantes (nueve montajes):

\begin{tabular}{|l|l|}
\hline \multicolumn{1}{|c|}{ Edición } & \multicolumn{1}{c|}{ Don Quijote de la Mancha } \\
\hline 2012 & Quijote: El doncel del caballero (La Quimera de Plástico) \\
\hline 2015 & Sanchica, princesa de Barataria (Estival Producciones) \\
\hline 2016 & $\begin{array}{l}\text { Don Quijote en la patera (Teatro Clásico de Sevilla) } \\
\text { Quijote, el vértigo de Sancho (Markeliñe Teatro, 2016) }\end{array}$ \\
\hline 2017 & $\begin{array}{l}\text { De un Quijote (Teatre Nu) } \\
\text { Dulcinea, locura quijotesca (Compañía del Revés) }\end{array}$ \\
\hline 2018 & $\begin{array}{l}\text { El libro andante (Maní Obras Teatro) } \\
\text { Aventuras de Don Quijote (El Retablo) }\end{array}$ \\
\hline 2019 & El hermano de Sancho (Laurentzi Producciones) \\
\hline
\end{tabular}

William Shakespeare (once montajes):

\begin{tabular}{|c|c|c|c|c|c|c|}
\hline Edición & Romeo y Julieta & Hamlet & La Tempestad & Noche de Reyes & Enrique $V$ & Varios \\
\hline 2012 & $\begin{array}{l}\text { Romeo y Julieta } \\
\text { (Albero Teatro) }\end{array}$ & & & & & $\begin{array}{l}\text { La hija de Sha- } \\
\text { kesperare (La } \\
\text { Mar de Mario- } \\
\text { netas) }\end{array}$ \\
\hline 2013 & $\begin{array}{l}\text { Romeo y Julie- } \\
\text { ta, una obra en } \\
\text { construcción } \\
\text { (Puro Grupo) }\end{array}$ & & & & & \\
\hline 2014 & & $\begin{array}{l}\text { Hamlet, un } \\
\text { viaje de ida y } \\
\text { vuelta (Colec- } \\
\text { tivo Artístico } \\
\text { Antrópolis) }\end{array}$ & & $\begin{array}{l}\text { Noche de Reyes } \\
(\text { Coart }+\mathrm{E})\end{array}$ & & \\
\hline 2015 & $\begin{array}{l}\text { Romeo y Julie- } \\
\text { ta de bolsillo } \\
\text { (Compañía } \\
\text { Criolla) }\end{array}$ & & $\begin{array}{l}\text { La tempestad } \\
\text { (La companyia } \\
\text { del príncep } \\
\text { Totilau) }\end{array}$ & & & \\
\hline 2016 & & & & & $\begin{array}{l}\text { ¿Qué con Qui- } \\
\text { que V? } \\
\text { (Cabaret Mis- } \\
\text { terio y Efe Tres } \\
\text { Teatro) }\end{array}$ & \\
\hline 2017 & & & & & & $\begin{array}{l}\text { Shakespireando } \\
\text { (Canta Circo\&- } \\
\text { Teatro) }\end{array}$ \\
\hline 2018 & & & $\begin{array}{l}\text { Una tempestad } \\
\text { (Compañía Tea- } \\
\text { tral Antrópolis) }\end{array}$ & & & \\
\hline 2019 & & & & & & $\begin{array}{l}\text { La fórmula } \\
\text { Shakespeare, } \\
\text { un método poco } \\
\text { científico (Polo } \\
\text { Sur) }\end{array}$ \\
\hline
\end{tabular}

Asimismo, pero muy lejos de esto números, podemos encontrar a: 
Pedro Calderón de la Barca (cuatro montajes):

\begin{tabular}{|l|l|l|}
\hline Edición & \multicolumn{1}{|c|}{ La vida es sueño } & \multicolumn{1}{|c|}{ El mágico prodigioso } \\
\hline 2013 & $\begin{array}{l}\text { La vida es sueño: Segismundo, el príncipe } \\
\text { prisionero (Pitbull Teatro) }\end{array}$ & \\
\hline 2014 & & \\
\hline 2015 & Cuentos de oro (Escaramuza Teatro) $)^{3}$ & El mágico prodigioso (El Viaje Entretenido) \\
\hline 2016 & $\begin{array}{l}\text { Y los sueños, sueños son (Tropos, teatro de } \\
\text { títeres y La Tirita Teatro) }\end{array}$ & \\
\hline
\end{tabular}

Lope de Rueda (dos montajes)

\begin{tabular}{|l|l|}
\hline Edición & \multicolumn{1}{|c|}{ Pasos } \\
\hline 2012 & Julia, un viaje teatrásico (Teatro Clásico de Sevilla) \\
\hline 2019 & La corte de los bufones: paso a paso la comedia (La Gorgona Teatro) \\
\hline
\end{tabular}

Lope de Vega (dos montajes):

\begin{tabular}{|l|l|l|}
\hline Edición & \multicolumn{1}{|c|}{ La dama boba } & \multicolumn{1}{|c|}{ Obra lírica } \\
\hline 2015 & $\begin{array}{l}\text { La dama boba (en versión animal) (Compa- } \\
\text { ñía de Teatro La Calderona) }\end{array}$ & $\begin{array}{l}\text { Mi príncipe azul (El ballet imperial de la rei- } \\
\text { na Rosamunda) }\end{array}$ \\
\hline 2017 & & nama \\
\hline
\end{tabular}

La vida de Lazarillo de Tormes y de sus fortunas y adversidades (dos montajes):

\begin{tabular}{|l|l|}
\hline \multicolumn{1}{|c|}{ Edición } & \multicolumn{1}{|c|}{ La vida de Lazarillo de Tormes y de sus fortunas y adversidades } \\
\hline 2016 & Lazarillo (Arden Producciones) \\
\hline 2017 & Lazarillo (Claroscuro) \\
\hline
\end{tabular}

La mayor o menor presencia de los autores y la obra anteriormente citados, en Barroco Infantil, desde su creación en 2012 hasta el verano de 2019, podemos apreciarla visualmente en el siguiente gráfico:

\section{Autores más representados en "Barroco Infantil"}

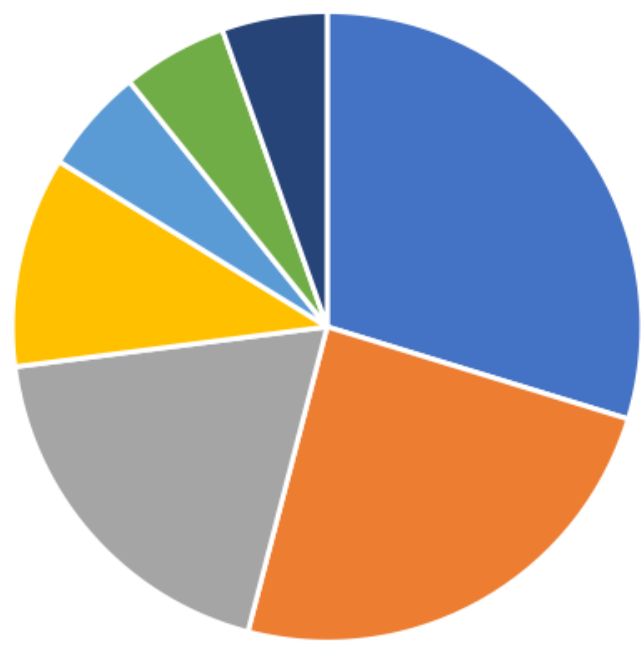

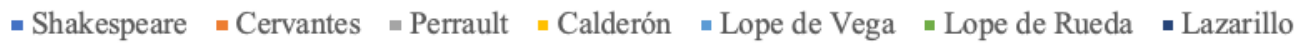


En la revisión de todos estos programas, llama la atención la escasa presencia de textos y autores de nuestro teatro áureo. El patrimonio del teatro barroco español es ingente y la calidad de muchas de sus obras incuestionable, no solo a nivel artístico, sino también a nivel humano por los temas, sentimientos, pasiones y miserias que en ellas se reflejan, por todo aquello que realmente convierte a estas piezas en clásicas, pues, a pesar de los siglos pasados, seguimos viéndonos representados y aprendiendo de y con ellas. Las carteleras de los demás festivales muestran un panorama muy similar, excepto en el caso de Olmedo Clásico ${ }^{4}$ : Shakespeare, único autor presente en todas las ediciones y, especialmente, con Romeo y Julieta, reina, junto con múltiples versiones del Quijote. Ante esta situación, pueden plantearse diversas cuestiones como: ¿por qué Shakespeare es el autor más versionado en España? ¿Realmente los argumentos de tragedias como Romeo y Julieta, Hamlet o Enrique $V$ o comedias como Noche de Reyes o La tempestad, son más apropiados para un público infantil que los de las grandes tragedias y dramas de nuestro áureo como $L a$ vida es sueño, El castigo sin venganza, El caballero de Olmedo, o comedias como La dama boba, El perro del hortelano o La dama duende? Debemos tener en cuenta que, además, el público al que van dirigidos estos montajes es más infantil que juvenil, por lo que una historia de amor como la de Romeo y Julieta no refleja tanto las inquietudes de un niño, como podría ser en el caso de un público adolescente. Asimismo, también podría cuestionarse por qué se recurre insistentemente a adaptar textos narrativos como los cuentos de Perrault o el Quijote, dejando al margen textos que desde su inicio fueron concebidos para el teatro.

Más que por cuestiones de calidad o idoneidad, las compañías se podrían haber dejado llevar en su elección especialmente por dos motivos:

- La elección de títulos más conocidos por el público general, no solo el aficionado al teatro clásico, y que son especialmente conocidos por sus versiones cinematográficas, como sería el caso de las obras de Shakespeare. También aquellas que resultan especialmente familiares a los niños como los cuentos de Perrault o parten de la obra más famosa y reconocida de nuestra literatura, como es el Quijote. Esto podría ofrecer seguridad a la hora de conseguir ser programados y de que asista el mayor público posible a sus funciones.

- La visión generalizada de nuestro teatro áureo como de un teatro retrógrado y con un público, hasta hace relativamente poco tiempo, muy reacio a las versiones, revisiones o actualizaciones de estas piezas.

Sin embargo, poco a poco y, principalmente gracias a la labor de compañías especializadas en teatro clásico, como Corsario o Noviembre teatro, así como la llevada a cabo en la Compañía Nacional de Teatro Clásico por Eduardo Vasco y Helena Pimenta, estas ideas han ido cambiando y es cada vez mayor el público que, por un lado, reconoce en nuestros clásicos sentimientos, situaciones y lecciones aplicables a nuestra contexto y, por otro, que sabe apreciar tanto montajes canónicos, como apuestas más arriesgadas.

No se puede dudar de que niños y jóvenes son capaces de disfrutar y aprender con montajes sobre piezas de Shakespeare, Perrault o Cervantes, entre otros. Lo que aquí se plantea es que no tienen por qué ver una y otra vez las mismas piezas, habiendo otras fuentes clásicas, de gran calidad, variedad y de nuestra propia cultura, con las que las compañías pueden trabajar. Afortunadamente, varios profesionales del teatro para niños han decidido apostar por diferentes piezas del teatro barroco español y, como resultado, podemos encontrar diversos montajes de gran originalidad y calidad, y que han tenido una gran acogida de público.

Compañía pionera en este tipo de montajes fue Pie Izquierdo. En 2008, estrenó en el Festival de Olmedo Clásico una versión infantil de La dama boba, de Lope de Vega, realizada por la filóloga, dramaturga y directora Esther Pérez Arribas. Las palabras de Pérez Arribas sobre por qué hizo este montaje reflejan magníficamente lo anteriormente expuesto:

La idea de adaptar un clásico de nuestro Siglo de Oro surge de la constatación de que no existen adaptaciones para niños, ni de textos de Lope de Vega ni de otros autores de este brillante periodo de la literatura dramática española. Así que pensamos que, si hay multitud de versiones de obras de Shakespeare dirigidas a este público, por qué no iba a ser posible hacerlo con una obra de Lope. [...] Poner en el escenario una obra tan importante en nuestra tradición cultural y mostrar a los niños unos personajes que hablan en verso, pero que tienen unos conflictos parecidos a los suyos, nos pareció una labor fascinante y que de algún modo podía paliar el desconocimiento de la mayoría de los niños de nuestro país sobre los autores de nuestra tradición dramática [Pérez Arribas 2012: 3].

Acorde con estas palabras, Pérez Arribas mantiene el verso en todo el montaje y realiza una versión llena de musicalidad -además de por el verso, por la presencia de varias canciones y bailes- y de color. Una puesta en escena que resulta muy atractiva visual y sonoramente para los niños y que les presenta, a través de sus protagonistas, Nise y Finea, conflictos propios de su vida cotidiana como "los celos o la rivalidad entre hermanos, la autoridad de los padres, las relaciones en la escuela o el primer amor" [Cienfuegos 2019: 18]. La duración aproximada

\footnotetext{
En este festival, se han programado los siguientes clásicos para niños: El sueño de una noche de verano (2007, Alquibla Teatro); La dama boba (2008, Pie Izquierdo); El caballero de Olmedo (2011, Aula de teatro de la Universidad de Murcia); El gran mercado del mundo (2011, Pie Izquierdo); Sonetos entre todos (2014, Pie Izquierdo); La dama boba (2015, Pie Izquierdo); El mágico prodigioso, (2016, El Viaje Entretenido); Y los sueños, sueños son (2018, Tropos Teatro); Érase otra vez... Romeo y Julieta (2019, PupaClown). Por tanto, se puede ver cómo aquí se invierten los números y, de entre los ocho montajes programados entre 2007 y 2019, tan solo dos son adaptaciones de obras de Shakespeare, mientras los otros montajes se nutren de textos de nuestro teatro áureo: dos pertenecen a Lope de Vega y tres a Calderón. En el caso de Sonetos entre todos, el guion incluye versos de Lope de Vega y Sor Juana Inés de la Cruz, que pronuncian dos títeres que representan a ambos poetas.
} 
de este espectáculo es de 60 minutos y se recomendó para niños a partir de 6 años. Respecto a la obra original, para reducirla y adaptarla al público infantil, Pérez Arribas principalmente eliminó personajes y fragmentos secundarios, pero para enlazar secuencias, creó un personaje narrador, el maestro Don Rufino, que ayudaba a los niños a seguir la trama, un recurso propio del teatro familiar. Tras el éxito de La dama boba, en 2011, Pie Izquierdo se atrevió con un reto aún más complejo: una versión infantil del auto sacramental de Calderón El gran mercado del mundo. En su adaptación, la autora conservó, por un lado, la idea principal de Calderón del mundo como un mercado, en el que hasta cualidades o atributos inmateriales pueden comprarse; y por otro, la presencia de personajes alegóricos, propios del género del auto sacramental. El protagonista es un niño llamado Eugenio que quiere ser músico y es enviado por sus padres al "mercado del Mundo". Aquí, una serie de personajes alegóricos (Prisa y Paciencia, Soberbia y Humildad...) le tratan de vender sus mercancías. El niño unas veces acertará y otras errará en sus elecciones, pero luchará hasta el final por encontrar el camino que le conduzca a su objetivo, aprendiendo de las equivocaciones. Tal y como se describe en el dosier informativo de la obra, el uso de títeres, danza, verso, canciones y música en directo permite otorgar un tono festivo a la representación para, así, lograr "presentar emociones y comportamientos humanos, que los niños pueden identificar y, con una gran dosis de sentido del humor, se muestra el mundo como un mercado en donde lo verdaderamente valioso, ni se compra, ni se vende, se lucha por ello" [Pérez Arribas 2011b: 2]. En las dos adaptaciones de Pie Izquierdo encontramos como denominador común la búsqueda de trasmitir una serie de valores en los niños, entre los que el esfuerzo y el trabajo para lograr nuestros objetivos están muy presentes. Asimismo, para que los niños disfruten y reciban mejor el mensaje, ambos montajes contaron con protagonistas con los que pudieran sentirse identificados: dos hermanas adolescentes y un niño. Además, las máscaras y el color determinan el vestuario y el verso y la música en directo dotan de un ritmo vivo y alegre a ambos montajes, con el que mantienen viva la atención de los niños durante la representación.

De nuevo con Lope de Vega como autor de referencia, la compañía Sol y Tierra. Teatro de Títeres, especializada en teatro familiar, nos sorprende con una original adaptación de Fuenteovejuna, en la que el rey es un pastor, el pueblo su rebaño y el comendador, el perro encargado de vigilarlo. El uso de los títeres es otro de los motivos fundamentales dentro del teatro familiar. No solo por cómo pueden llamar la atención los muñecos a los niños y porque permitan a las compañías jugar con un mayor número de personajes con un menor número de actores, sino porque es un medio excelente para acercar a los niños a historias, personajes y acciones que, representadas por personas, pudieran resultarles más sobrecogedoras o complejas de asimilar, por paradójico que parezca. El distanciamiento que dan los títeres ayu- da a que los niños perciban la representación con menor tensión y acepten mejor cualquier convención dramática. Los muñecos son movidos por dos actores a los que la mayor parte vemos en escena. En esta original versión de Sol y Tierra, recurren, asimismo, a otro importante recurso para acercar a los niños historias con las que pretendemos hacerles llegar determinados valores y enseñanzas: la fábula y protagonistas animales. La obra se desarrolla en un cuarto de baño, al que los actores van a asearse, una situación de lo más cotidiana. Pero las toallas toman las formas de las ovejas y del perro pastor y la historia se desarrolla sin apenas diálogos. Los balidos, gruñidos y ladridos de los animales resultan suficientes para transmitir los sentimientos de los personajes que disfrutan, sufren y se rebelan ante los hechos que van acaeciendo. En el dosier realizado por la compañía, nos dan las claves de su montaje y del mensaje que quieren trasmitir a los niños a partir de la genial obra de Lope:

Recuperamos el fondo de la dramaturgia, la unión del pueblo contra los abusos de los poderosos, y aprovechamos esto para destacar la importancia del poder de un grupo de cara a detener el abuso. Recalcamos el sentido de la justicia, la valentía y el apoyo mutuo como valores que pueden ayudar a prevenir el acoso escolar y hacer a los niños y niñas menos tolerantes ante la justicia [Compañía Sol y Tierra 2019b].

Es por ello por lo que el perro, que representaría al comendador, no llega a morir y es perdonado y readmitido por los protagonistas. Con ello, vemos cómo de una obra que en su versión original sería excesivamente dura y compleja para un público infantil, se puede extraer un mensaje que se corresponde con una problemática muy actual y que, desgraciadamente, también está presente en su día a día .

De entre los textos dramáticos escogidos por las compañías españolas para versionar un clásico, destaca, por ser del que más adaptaciones se han llevado a cabo, el de La vida es sueño. En este trabajo se analizan dos de las propuestas: una adecuada para público infantil (a partir de 6 años) y otra para público juvenil, pues se ha diseñado especialmente para estudiantes de entre tercero de la ESO y primero de Bachillerato, cursos en los que el teatro barroco está en el programa.

La primera de ellas, el montaje que se destina un público de menor edad, lo debemos a Tropos, teatro de Títeres y La Tirita de Teatro y obtuvo una gran acogida no solo de público, sino también por parte de la crítica: fue candidato en 2015 en los premios Max como mejor espectáculo infantil y recibió Mención especial en el certamen de Barroco Infantil de 2017. En esta versión, de nuevo los títeres juegan un papel fundamental. Los personajes de Clotaldo y Clarín, representados por dos actores, son los encargados de narrar con sus títeres la historia de Segismundo, en la que se toman diversas licencias, como que el protagonista a quien tira por la

Con esta vía de trabajo siguen la línea ya marcada en 2108 en la versión de su primer clásico, el montaje El ratón de la Mancha. Como por su nombre puede intuirse, está inspirada en el Quijote y también busca conciliar un texto clásico con el trabajo de valores que responden a necesidades atemporales y, al mismo tiempo, muy cercanas a los niños del siglo XXI: animar a la lectura y mostrar los beneficios de la resolución pacífica de conflictos. Véase la información de su página web: http://www.solytierra.com/obras $\% 20 \mathrm{de} \% 20$ teatro $\% 20 \mathrm{de} \% 20$ titeres $\% 20-\% 20$ el $\% 20$ raton $\% 20$ de\%201a\%20mancha.htm (Fecha de consulta: 19-01-20). 
ventana no es a un criado, sino a Astolfo y después a Rosaura. Y, a pesar de ello, al final Astolfo y Estrella se casan, por un lado, mientras Segismundo y Rosaura también contraen nupcias tras la conversión del príncipe en un hombre justo y comedido. Los dramaturgos presentan su versión planteando las siguientes preguntas:

¿Acaso es justo encerrar a un hombre por lo que dictan las estrellas? ¿Por su lengua, su color, por su raza, por lo que puede llegar a hacer sin haber hecho nada? ¿Se puede esperar de un hombre que sea justo si nunca nadie le enseñó lo que era la piedad y el amor? ¿Se cumplirá acaso el vaticinio de las estrellas? [Gil Villanueva 2014b: 1].

La versión del texto es, asimismo, bastante libre, pero conserva algunos de los fragmentos de la obra, momento en el que los actores y sus títeres abandonan la prosa y se acogen al verso. Es curioso, por ejemplo, cómo introducen unos de los versos más conocidos, pero también complejos desde el punto de vista lingüístico de la pieza: los pronunciados por Rosaura al comienzo de la obra cuando cae de su caballo. La escena la representan los dos protagonistas con unas marionetas y juegan con los movimientos del caballo para que los niños entiendan a quién dedica Rosaura sus famosas palabras:

(Clotaldo hace ver que estalla un vendaval, el caballo se asusta y Rosaura acaba en el suelo).

R- Aaaaaaaaaaaaaaaaaaahhhhhhh. ¡Ay, qué torta me he pegado!

\section{(El caballo le hace monerías)}

(El caballo se acerca a pedir disculpas)

R- ¡Ala, ala, quita, hipogrifo violento!

C- ¿Hipogrifo violento?

R- ¡Hipogrifo violento

que corriste tanto como el viento,

quédate en este monte,

donde tengan los brutos su Faetonte! (Se va el caballo)

Mal, Polonia, recibes

a un extranjero, pues con sangre escribes

su entrada en tus arenas,

y apenas llega, cuando llega a penas;

bien mi suerte lo dice;

mas, ¿dónde halló piedad un infelice?

C- Di dos, y no me dejes

en la posada a mí cuando te quejes; [Gil Villanueva $2014 \mathrm{a}]^{6}$.

En el montaje de Tropos, la discusión esencial sobre el libre albedrío y la necesidad de conocer la responsabilidad y asumir las consecuencias de nuestros actos, temas fundamentales de la obra de Calderón, se plantean también a los niños y se les muestra, asimismo, cómo, si rectificamos y aprendemos de nuestros errores, la vida nos ofrece nuevas oportunidades. No se puede negar que el personaje de Segismundo es uno de los más completos, complejos y extraordinarios de la literatura universal con el que se plantean estas cuestiones fundamentales del comportamiento humano. No podemos desaprovecharlo.

Así lo creen también en la compañía Miseria y Hambre Producciones. Su montaje es un bululú. Un actor, Jaime Soler Huete, especializado en representar teatro clásico $^{7}$, cuenta, explica y comenta la historia de Segismundo, al tiempo que representa sus monólogos y escenas más relevantes con el apoyo de las nuevas tecnologías: una compañía de teatro virtual, que se proyecta en los objetos con los que Soler juega en el tablado, es la encargada de las escenas de varios personajes, mientras Soler interpreta a Segismundo en sus monólogos. La duración del montaje, al igual que la de los anteriores, es en torno a una hora. Está diseñado para poder ser representado en salones de actos, gimnasios o incluso aulas de centros educativos y en el tiempo medio de una clase. Desde la compañía, nos muestran en su dosier una serie de intereses pedagógicos que plantean con su montaje:

- Acercar al público joven La vida es sueño desde un lenguaje actual y dinámico por medio de las nuevas tecnologías y el videomapping.

- Trabajar la empatía respecto de Segismundo y la adolescencia.

- Realizar una dramaturgia desde la igualdad de género. El papel de Rosaura.

- Explicar la representación histórica y los mecanismos del teatro Barroco.

- Mostrar el teatro como espacio para el planteamiento de dilemas filosóficos del ser humano.

- Reflexionar sobre la vida y la virtualidad del sueño de la realidad como un continuo de tiempo que nos obliga a ser responsable de nuestros actos. [Miseria y Hambre Producciones 2019b: 2]

Esta rompedora apuesta aúna a la perfección el texto de Calderón con la tecnología actual y logra plantear a los jóvenes a los que se dirige, de una forma clara y cercana, los grandes dilemas filosóficos del drama calderoniano, acercándolos a la realidad de un adolescente del siglo XXI.

Junto a estos montajes comentados, cabría resaltar también la versión de la Pitbull Teatro de Segismundo, el príncipe prisionero, representada en la edición de 2013 de Barroco Infantil y candidata al premio de "Mejor espectáculo infantil" en los premios Max de 2014.

Se cierra esta panorámica con otra adaptación de un texto de Calderón, que destaca por su originalidad

\footnotetext{
Quisiera agradecer a Guillermo y Raquel, de Tropos Teatro, la amabilidad y disponibilidad con las que atendieron mi petición de materiales sobre su montaje de $Y$ los sueños, sueños son y por facilitarme su adaptación inédita del texto. También quiero agradecer la cordialidad y ayuda de Enrique Torre, de la Compañía Sol y Tierra y de Yolanda Mancebo, directora de El Viaje Entretenido. Asimismo, quisiera agradecer la inestimable ayuda de Esther Pérez Arribas, directora de Pie Izquierdo, pues sus adaptaciones son las que iniciaron la investigación llevada cabo en este trabajo y sus indicaciones fueron fundamentales para llegar a otros de los montajes aquí descritos.

Ha desempeñado papeles protagonistas en tres montajes de la Compañía Nacional de Teatro Clásico: La estrella de Sevilla (2009), El condenado por desconfiado (2010) y El alcalde de Zalamea (2011).
} 
y belleza estética: la de la compañía manchega El Viaje Entretenido de El mágico prodigioso de Calderón, adaptado y dirigido por Yolanda Mancebo. A partir de una imagen, una mariposa, se cuenta una lectura contemporánea y alegórica del tema principal de la obra: el descubrimiento de la fe, de Dios, que, para la creadora de la adaptación, es la belleza. Para focalizar la atención de los espectadores en el tema principal, prescinde de la trama secundaria, la de los amores y celos entre Floro, Lelio y Justina. A los dos graciosos, los convierte en dos mascotas de Cipriano, un gato y un perro, metáfora de la mala relación entre ambos personajes en la obra original. El Demonio se convierte en una suerte de mago que falla con los trucos, un falso prestidigitador que resulta un personaje divertido. Por su parte, la protagonista, Justina, es una amante de los libros y sabe extraer de ellos las imágenes más hermosas representadas en su amiga la mariposa, con la que ríe y disfruta. Es por ello por lo que Cipriano la anhela como amiga de juegos y compañera, pero no sabe cómo leer para encontrar el placer que demuestra Justina. Se trata de un montaje de gran sensibilidad artística, lleno de simbolismo, y en el que confluyen en el escenario muy diversos recursos como la música en directo, los títeres (las mascotas de Cipriano y la mariposa), la danza e, incluso, el circo, pues la obra comienza y finaliza con Justina volando y haciendo equilibrios con largas telas que cuelgan del techo.

A partir de todas las cuestiones aquí planteadas y de los montajes descritos, se ha pretendido mostrar no solo la idoneidad del teatro barroco español como fuente para montajes infantiles y juveniles, sino también lo beneficioso que puede resultar para este tipo de público el conocer a nuestros clásicos y aprender sobre el comportamiento humano. Ver que sus vivencias y sentimientos no son exclusivos, sino atemporales e inherentes al hombre, y descubrir cómo afrontar nuestras pasiones, deseos y equivocaciones, a través de unos personajes que, pareciendo tan lejanos, pueden estar tan cerca de ellos. Se ha hablado de Lope de Vega y de Calderón de la Barca porque son los dos máximos exponentes de nuestro teatro áureo, pero hubo dos generaciones de dramaturgos y dramaturgas que nos dejaron un patrimonio excepcional del que deberíamos sentirnos orgullosos y con el que niños, jóvenes y adultos podemos aprender y disfrutar.

\section{Referencias bibliográficas}

Almagro.35 Festival Internacional de Teatro Clásico. 5/29 de julio 2012, Fundación Festival Internacional de Teatro Clásico de Almagro. Recurso web < https://festivaldealmagro.com/uploads/files/programa_2012.pdf >, Fecha de consulta: 19-I-20.

Almagro.36 Festival Internacional de Teatro Clásico. 4/28 de julio 2013, Fundación Festival Internacional de Teatro Clásico de Almagro. Recurso web $<$ https://festivaldealmagro.com/uploads/files/programa_2013.pdf >, Fecha de consulta: 19-I-20.

Almagro.37 Festival Internacional de Teatro Clásico. 3/27 de julio 2014, Fundación Festival Internacional de Teatro Clásico de Almagro. Recurso web < https://festivaldealmagro.com/uploads/files/programa_2014.pdf >, Fecha de consulta: 19-I-20.

Almagro.38 Festival Internacional de Teatro Clásico. 2/26 de julio 2015, Fundación Festival Internacional de Teatro Clásico de Almagro. Recurso web $<$ https://festivaldealmagro.com/uploads/files/programa_2015.pdf $>$, Fecha de consulta: 19-I-20.

Almagro.39 Festival Internacional de Teatro Clásico. 7/31 de julio 2016, Fundación Festival Internacional de Teatro Clásico de Almagro. Recurso web < https://festivaldealmagro.com/uploads/files/FITCA16_Poficial_Interiores_AF.pdf $>$, Fecha de consulta: 19-I-20.

Almagro.40 Festival Internacional de Teatro Clásico. 6/30 de julio 2017, Fundación Festival Internacional de Teatro Clásico de Almagro. Recurso web < https://festivaldealmagro.com/uploads/files/FITCA17_PROGRAMA_AF.pdf $>$, Fecha de consulta: 19-I-20.

Almagro.41 Festival Internacional de Teatro Clásico. 5/29 de julio 2018, Fundación Festival Internacional de Teatro Clásico de Almagro. Programa impreso.

Almagro.42 Festival Internacional de Teatro Clásico. 4/28 de julio 2019, Fundación Festival Internacional de Teatro Clásico de Almagro. Programa impreso.

Cienfuegos Antelo, Gema (2019): “Introducción”, en Clásicos en Pie (Izquierdo). Teatro para la infancia, Valladolid, Ediciones de la Universidad de Valladolid/Ayuntamiento de Olmedo, 11-32.

Compañía Miseria y Hambre Producciones (2019a): Vida=Sueño, adaptación de La vida es sueño, de Pedro Calderón de la Barca, Centro de Artes Escénicas San Pedro, Olmedo, 16-VII, representación teatral.

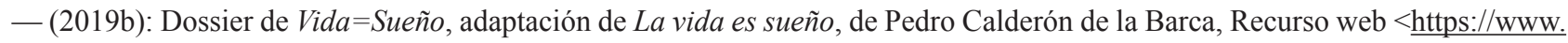
miseriayhambre.com/images/PDF/dossier-la-vida-igual-a-sueno.pdf $>$, Fecha de consulta: 19-01-20.

Compañía Sol y Tierra. Teatro de títeres (2019a), Guion de Fuenteovejuna, inspirada en la obra de Lope de Vega.

- (2019b), Dossier del montaje de Fuenteovejuna, inspirada en la obra de Lope de Vega, Recurso web < $\underline{\text { http://www.solytierra. }}$ com/index htm files/Dosier\%20Fuenteovejuna\%20-\%20Sol\%20y\%20Tierra\%20Teatro\%20-\%20Largo.pdf $>$, Fecha de consulta: $19-\mathrm{I}-20$.

Clásicos en Alcalá, Comunidad de Madrid/Ayuntamiento de Alcalá de Henares, Recurso web < $\underline{\text { http://www.clasicosenalcala. }}$ net/2020/home/>, Fecha de consulta: 19-I-20.

Festival de teatro clásico de Almagro, Fundación Festival Internacional de teatro clásico de Almagro, Recurso web $<\underline{\mathrm{https}} / / /$ festivaldealmagro.com/es/home/index.php>, Fecha de consulta: 19-II-20.

Festival de teatro clásico de Cáceres, Diputación de Cáceres/Ayuntamiento de Cáceres/Junta de Extremadura, Recurso web $<\underline{\text { https:// }}$ www.granteatrocc.com/clasico/2019/>, Fecha de consulta: 19-II-20. 
Gil Villanueva, Guillermo (2014a): Adaptación de La vida es sueño, Pedro Calderón de la Barca, Tropos teatro de títeres/La Tirita Teatro. Texto inédito.

- (2014b): Dossier de La vida es sueño, Pedro Calderón de la Barca, Tropos teatro de títeres/La Tirita Teatro.

- (2014c): La vida es sueño, Pedro Calderón de la Barca, Teatro Coliseo de Palma, Palma del Río, 26-I, representación teatral. Recurso web <https://www.youtube.com/watch?list=UU5uxc9zMXai 7NKrfMK9hXg\&v=FXSQTMX1eyM>, Fecha de consulta: 19-I-20.

Mancebo Salvador, Yolanda (dir.) (2015a): El mágico prodigioso, Pedro Calderón de la Barca, Teatro Municipal, Almagro, 9-VII, representación teatral.

- (adap.) (2015b): Dossier de El mágico prodigioso, Pedro Calderón de la Barca, Compañía El Viaje Entretenido.

Olmedo clásico, Ayuntamiento de Olmedo, Recurso web <http://www.olmedo.es/olmedoclasico/>, Fecha de consulta: 19-I-20.

Pérez Arribas, Esther (dir.) (2008): La dama boba, adaptación del auto de Lope de Vega, Centro de Artes Escénicas San Pedro, Olmedo, 26-VII, representación teatral.

- (dir.) (2011a): El gran mercado del mundo, adaptación del auto de Pedro Calderón de la Barca, Centro de Artes Escénicas San Pedro, Olmedo, 19-VII, representación teatral.

- (2011b): Dossier de El gran mercado del mundo, adaptación del auto de Pedro Calderón de la Barca, Compañía Pie Izquierdo.

- (2012): "Los clásicos van a la escuela", Anagnórisis. Revista de investigación teatral, 5, 1-10.

- (2019a): La dama boba, adaptación de la obra de Lope de Vega, en Clásicos en Pie (Izquierdo). Teatro para la infancia, Valladolid, Ediciones de la Universidad de Valladolid/Ayuntamiento de Olmedo, 33-74.

- (2019b): El gran mercado del mundo, adaptación de la obra de Calderón de la Barca, en Clásicos en Pie (Izquierdo). Teatro para la infancia, Valladolid, Ediciones de la Universidad de Valladolid/Ayuntamiento de Olmedo, 75-114. 